\title{
Timely Review
}

\section{PREGNANCY AND COVID-19: A BRIEF REVIEW}

\author{
Olga Vasylyeva, $\mathrm{MD}^{1}$ *
}

Author information: ${ }^{1}$ Infection Disease Department, Rochester General Hospital; 1425 Portland Ave, Rochester, NY 14621; email: olga.vasylyeva@rochesterregional.org

\begin{abstract}
COVID-19 is a disease caused by the novel coronavirus (CoV) that can result in a severe acute respiratory syndrome. Pregnant women have a complex modification of the immune system that varies through pregnancy and extends to the postpartum period. Change in the balance toward antiinflammatory pathways occurs, although some cellular mechanisms of immunity could be enhanced. Overall, pregnant women tend to have more severe viral illnesses as compared with the general population as reported in influenza, varicella, herpes simplex, and Ebola infections. Previous outbreaks of coronavirus diseases, SARS-CoV, and MERS-CoV demonstrated rather a small number of reported cases, mixed outcomes for mothers and neonates, and the absence of vertical transmission. COVID-19 appears to follow a similar pattern; however, it is more contagious, and additional data will likely emerge soon. Due to immunological and physiological changes in pregnancy, more severe outcomes for other viral infections, and presently scarce data on COVID-19, the reasonable approach is to consider pregnant women an at-risk population.
\end{abstract}

Key words: COVID-19, coronavirus, women, pregnancy, neonates

INTRODUCTION COVID-19 is a disease caused by the novel coronavirus that can result in a severe acute respiratory syndrome. First identified in December, 2019, in Wuhan, China, the virus spread around the world and is characterized as a pandemic by the World Health Organization [1,2]. According to Johns Hopkins Coronavirus Resource Center, on March 17, 2020, confirmed cases surpassed 189,160 with a total of 7,497 deaths around the world, among them 5068 cases in the US and 85 deaths [3]. This article summarizes what is presently known about COVID-19 in pregnant women and reviews the unique risk factors for severity of viral illnesses among pregnant women.

IMMUNE SYSTEM AND PREGNANCY Women's bodies undergo immunological changes during pregnancy to avoid rejection of the fetus and placenta. The historical paradigm presents pregnancy as an immunocompromised state, but more recent data suggest that it is a modified immune state that might increase the severity of some infections without increasing susceptibility for acquisition $[4,5]$. A woman's immune response might change at different trimesters and during the postpartum period, shifting from a pro-inflammatory to an anti-inflammatory state. An increase in progesterone and estrogens significantly contributes to immune system modifications $[4,5]$. Some of the hormonal effects on immunity are summarized below:

HORMONES IN PREGNANCY Progesterone. Progesterone receptors are present on immune cells, such as macrophages, dendritic cells, and lymphocytes, and can bind to glucocorticoid receptors on these cells. An increased level of progesterone is associated with several anti-inflammatory effects [6].

- Progesterone reduces the production of proinflammatory interleukin (IL) -6 and IL-12 cytokines in a murine model [7].

- During the second trimester of pregnancy, progesterone induces the reduction of regulatory $\mathrm{T}$ cells, while preserving their activity [8].

- Contraception with medroxyprogesterone acetate is associated with suppression of $\mathrm{CD}^{+}$T-cell effector functions and reactivation of herpes simplex virus type 1 (HSV-1) [9].

- Elevated progesterone favors T helper type (Th)-2immune responses over Th-1-responses. The latter is 
International Journal of Integrative Pediatrics and Environmental Medicine, V5, 2020, 8-13

associated with the production of pro-inflammatory cytokines. The Th2-response counteractions to Th-1 appear to play an important role in sustaining pregnancy $[10,11]$.

- Progesterone is associated with reduced macrophage activity in the murine model $[6,12]$.

Estrogens. Estrogen receptors are present on lymphocytes, macrophages, and dendritic cells. The impact of estrogens on the immune system is described as paradoxical. Studies show an association of estrogens with suppression of inflammation, as well as pro-inflammatory effects [13].

- Estrogen can enhance tumor necrotic factor-alpha expression, while also suppressing pro-inflammatory cytokines at estrogen concentrations observed during pregnancy and is able to stimulate anti-inflammatory Th-2-associated pathways $[6,13]$.

- Estradiol elevates lipopolysaccharide-binding protein levels and expression of Toll-like receptors that play a role in antigen recognition. Inflammatory cytokine levels were much higher in vivo after a lipopolysaccharide challenge with increased endo-toxinassociated morbidity [14].

- Estradiol enhances interferon-gamma production in a mouse model [15].

- Estriol, the hormone absents in non-pregnant women and accounting for $90 \%$ of all estrogens in pregnancy [6], and estradiol can enhance bacteria-specific immunoglobulin (Ig) M antibody. However, estriol, unlike estradiol, does not affect the response against the soluble protein in the murine model. It was proposed that such a difference might be used to reduce antibody-mediated immune damage during pregnancy $[6,16]$.

POSTPARTUM Interferon-gamma, IL-2, and tumor necrosis factor-alpha are low during the postpartum period and take up to 3 months to return to normal [17].

The rebound of immune response postpartum has been linked to reactivation of dormant chronic diseases, or immune reconstitution syndrome, previously described concerning human immunodeficiency virus infection and organ transplant. Exacerbation of chronic hepatitis $C$ and hepatitis $B$, worsening cryptococcal infection, and a high incidence of extra-pulmonary tuberculosis have been reported in postpartum women [18].
RESPONSE TO VACCINATION Immunogenicity of non-live vaccines in pregnant women appears to be comparable with the general population.

- In a randomized trial, pregnant women vaccinated with Tdap (tetanus, diphtheria, and pertussis) or $\mathrm{Td}$ (tetanus and diphtheria booster) had a significant antibody response that peaked by the time of delivery or by two months postpartum [19].

- Pregnant women obtain an effective response to influenza vaccination, although the cellular response is not fully understood $[20,21]$.

On the other hand, as a precautionary measure, the administration of live vaccines during pregnancy is generally contraindicated, due to theoretical risk to the fetus $[22,23]$. In one study, pregnant women inadequately vaccinated with live yellow fever vaccine had a much lower level of protective antibody than a control group. In contrast, another study reported $98.2 \%$ of women were positive for IgG six weeks post-vaccination [23]. Overall, data on the immunogenicity of live vaccines and durations of protective immunity during pregnancy are insufficient.

NON-IMMUNOLOGICAL CHANGES Maternal adaptation in pregnancy can contribute to the severity of infectious diseases. Cardiac output increases by $40 \%$ during pregnancy and systemic vascular resistance drops due to peripheral vasodilation. Stroke volume and heart rate increase, and transition from lateral to a supine position may lead to a $25 \%$ decrease in cardiac output. Oxygen demand rises due to an increase in metabolic rate and oxygen consumption increases by up to $20 \%$. A rapid increase in cardiac output by $60-80 \%$ follows delivery; at that time venous return is increased, which puts a patient with cardiovascular issues at risk for pulmonary edema [24].

VIRAL INFECTION AND PREGNANCY Risk of increased severity of viral infections among pregnant patients is well documented.

Influenza During the 2009 influenza H1N1 pandemic, pregnant women had a high risk of morbidity compared to other groups. Approximately $23 \%$ of those hospitalized required admission to intensive care. Five percent of all reported influenza-related deaths were attributed to pregnant women (with only $1 \%$ of the US population being pregnant). Increased severity was likely due to 
International Journal of Integrative Pediatrics and Environmental Medicine, V5, 2020, 8-13

changes in immune, cardiac, and respiratory systems among pregnant women [25].

Herpes simplex virus (HSV) Pregnant women are at high risk for disseminated primary HSV infection and HSV hepatitis [4].

Varicella Primary varicella infection at the time of pregnancy is more often associated with pneumonia with a higher level of mortality than controls [4].

Ebola virus Pregnant women infected with the Ebola virus appear to have a higher risk of complications and death during all trimesters [26].

Severe acute respiratory syndrome (SARS) Only a small number of pregnant women with SARS caused by a SARS$\mathrm{CoV}$ was reported during the outbreak in 2003. Among twelve pregnant patients in Hong Kong, three women died (mortality 25\%) [27]. In two reports of SARS-CoV in pregnant patients in the US, none had such a severe outcome [28]. One patient had preterm labor with a healthy child [28]. Five SARS infections reported from China happened during the second and third trimesters. One fetus in a twin-pregnancy died, and the rest had no evidence of SARS-CoV infection [29].

Middle East respiratory syndrome (MERS) A case of the MERS coronavirus infection in a pregnant woman described in South Korea resulted in maternal recovery. This patient had suspected placenta abruption prompting a cesarean section. MERS-CoV tested negative in the neonate [30]. A report from the Kingdom of Saudi Arabia presented a 32-week pregnant woman with MERS-CoV required ventilation support and intensive care, who eventually recovered and delivered a healthy infant [31]. In a further case series of five pregnant women infected with MERS-CoV, all required ICU care, and two women died. One infant was stillborn, and another died shortly after birth [32].

In addition to increased severity of viral infection among pregnant women, some viruses are notoriously associated with birth defects, including rubella, cytomegalovirus, and Zika virus [33].

Maternal viral infection can activate inflammatory responses in the fetus even without detectable organism levels and result in fetal inflammatory response syndrome (FIRS). With this syndrome, the placenta has high concentrations of pro-inflammatory cytokines. In animals, FIRS is associated with fetal abnormalities [5].

\section{WHAT IS KNOWN ABOUT COVID 19 AND PREGNANCY?} Presently, very scarce data are available on the outcome for pregnant women with COVID-19 and recommenddations remain fluid. In a retrospective review of nine pregnant women in Wuhan, all had caesarian sections in the third trimester. None of the women had severe pneumonia or died, and all neonates had 5-minute Apgar scores of 9-10. No COVID-19 was detected in tested amniotic fluid, cord blood, breast milk, or neonatal throat swabs. Maternal age ranged from 26 to 40 years old with a median of 28 years. None of the patients received corticosteroids [34].

In another review of 10 neonates born to nine mothers with COVID-19, six infants were born premature, six had intrauterine distress, one died with multiple organ failure and disseminated intravascular coagulation (DIC), and four remained in the hospital at the time of the report. Two neonates had DIC and received transfusions. Nine neonates were tested with throat swabs and all were negative for COVID-19. The age of the pregnant women ranged from 25 to 35 years old with a median of 30 years. Seven women had cesarean section. Although similarly to SARS-CoV or MERS-CoV no vertical transmission was documented, it needs to be noted that SARS-CoV-2 is more contagious than former viruses [35].

In both studies, reported pregnancies were at the third trimester, data on the first and second trimesters are presently lacking.

The World Health Organization-China Joint mission reported on 147 pregnant patients with 64 confirmed, 82 suspected, and one asymptomatic case, among which $8 \%$ had severe and $1 \%$ had critical disease [1].

A non-pregnancy associated risk factor in COVID-19 infection is increased age. Deaths among patients in the age group of 20-49 years old range from $0.7-3.7 \%$ (case fatality rate $0.2-0.4 \%$ ). The risk of death increases dramatically with every decade. The severity of disease is expectedly associated with mortality (case fatality rate $49 \%$ for critical severity). Mortality among patients with comorbidities, including cardiovascular disease, diabetes, hypertension, chronic respiratory disease, and cancer are also proportionally higher [36]. 
International Journal of Integrative Pediatrics and Environmental Medicine, V5, 2020, 8-13

The American College of Obstetricians and Gynecologists (ACOG) developed an algorithm to aid in outpatient management of pregnant women with suspected or confirmed COVID-19. ACOG advises that based on the inferred data from influenza and SARS-CoV, pregnant women should be considered an at-risk population, although very limited factual data on COVID-19 is available. The primary concern for breastfeeding is the risk of droplet transmission [37].

CONCLUSION In conclusion, pregnant women have a complex modification of the immune system that varies through pregnancy and extends to the postpartum period. Change in the balance toward anti-inflammatory pathways occurs, although some cellular mechanisms of immunity could be enhanced. Overall, pregnant women tend to have more severe viral illnesses compared with the general population as reported in influenza, varicella, HSV, and Ebola infections. Previous outbreaks of coronavirus, SARS-CoV, and MERS-CoV demonstrated rather a small number of reported cases, mixed outcomes for mothers and neonates, and the absence of vertical transmission. COVID-19 appears to follow a similar pattern; however, it is more contagious, and additional data will likely emerge soon. Due to immunological and physiological changes in pregnancy, more severe outcomes for other viral infections, and presently scarce data on COVID-19, the reasonable approach is to consider pregnant women an at-risk population.

\section{REFERENCES}

1. World Health Organization. Report of the WHOChina Joint Mission on Coronavirus Disease 2019 (COVID-19). Available on-line: https://www.who.int/docs/defaultsource/coronaviruse/who-china-joint-mission-oncovid-19-final-report.pdf?fbclid=IwAR1kCfPkkBnSshMxATg_HA6Bm5YnloLKAXEI2SmTklooTJY42IcQ10I00.

2. World Health Organization. Coronavirus updates press release. WHO characterizes COVID-19 as a pandemic. 11 March 2020. Available online: https://coronavirus.jhu.eduhttps://www.who.int/e mergencies/diseases/novel-coronavirus2019/events-as-they-happen.

3. Johns Hopkins University of Medicine Coronavirus Resource Center. COVID-19 Map: https://coronavirus.jhu.edu/map.html?fbclid=IwARO
WthjsAIT3BkIApe7gjVazepLLf8rYMJohq7zEY2NgetQa 2wEwss4DNIA. (Last reviewed 3/17/2020)

4. Kourtis AP, Read JS, Jamieson D. Pregnancy and infection. N Engl J Med. 2014 Jun 5: 370(23): 22112218. Available online: https://www.ncbi.nlm.nih.gov/pmc/articles/PMC44 59512.

5. Racicot K, Kwon J-Y, Also P, Silasi M, Mor G. Understanding the complexity of the immune system during pregnancy. Am J Reprod Immunol. 2014 Aug; 72(2): 107-116. Available online: https://www.ncbi.nlm.nih.gov/pmc/articles/PMC68 00182/.

6. Robinson DP, Klein SL. Pregnancy and pregnancyassociated hormones alter immune response and disease pathogenesis. Horm Behav. 2012 Aug; 62(3) 263-271. Available online: https://www.ncbi.nlm.nih.gov/pmc/articles/PMC33 76705.

7. Jones LA,Kreem S, Shweash $M$, Paul $A$, et al. Differential Modulation of TLR3- and TLR4-Mediated Dendritic Cell Maturation and Function by Progesterone. J Immunol October 15, 2010, 185 (8) 4525-4534. Available online: https://doi.org/10.4049/jimmunol.0901155.

8. Mjösberg J, Svensson J, Johansson E, et al. Systemic reduction of functionally suppressive CD4 ${ }^{\text {dim }} C D 25^{\text {high }}$ Foxp3 ${ }^{+}$Tregs in Human Second Trimester Pregnancy Is Induced by Progesterone and 17ß-Estradiol. Available online: https://www.jimmunol.org/ content/183/1/759.long. Accessed 3/16/2020.

9. Cherpes TL, Busch JL, Sheridan BS, et al. Medroxyprogesterone Acetate Inhibits CD8 ${ }^{+} \mathrm{T}$ Cell ViralSpecific Effector Function and Induces Herpes Simplex Virus Type 1 Reactivation. J Immunol July 15, 2008, 181 (2) 969-975. Available online: https://doi.org/10.4049/jimmunol.181.2.969.

10. Piccinni MP, Giudizi MG, Biagiotti $R$, et al. Progesterone favors the development of human $\mathrm{T}$ helper cells producing Th2-type cytokines and promotes both IL4 production and membrane CD30 expression in established Th1 cell clones.J Immunol July 1, 1995, 155 (1) 128-133.

11. Berger $A$. Th1 and Th2 responses: what are they? BMJ. 2000 Aug 12; 321(7258): 424. Available online: 10.1136/bmj.321.7258.424.

12. Savita, Rai U. Sex steroid hormones modulate the activation of murine peritoneal macrophages: receptor mediated modulation. Comp 
International Journal of Integrative Pediatrics and Environmental Medicine, V5, 2020, 8-13

BiochemPhysiol C PharmacolToxicol Endocrinol.1998 Feb;119(2):199-204.

13. Straub RH. The complex role of estrogens in inflammation. Endocrine Reviews, Volume 28, Issue 5, 1 August 2007, Pages 521-574. Available online: https://doi.org/10.1210/er.2007-0001.

14. Rettew JA, Huet YM, Marriott I. Estrogens augment cell surface TLR4 expression on murine macrophages and regulate sepsis susceptibility in vivo. Endocrinology, 2009 Aug;150(8):3877-84. Available online: https://academic.oup.com/endo/article/ 150/8/3877/2456520.

15. Nakaya M, Tachibana $H$, Yamada K. Effect of Estrogens on the Interferon- $\gamma$ Producing Cell Population of Mouse Splenocytes. 2006 Volume 70 Issue 1 Pages 47-53.

16. Ding J, Zhu BT. Unique effect of the pregnancy hormone estriol on antigen-induced production of specific antibodies in female BALB/C mice. Steroids. 2008 Mar;73(3):289-98.

17. Groer ME, Jevitt C, Ji M. Immune changes and dysphoric moods across the postpartum. Am J Reprod Immunol. Available online: 10.1111/aji.12322.

18. Singh N, Perfect JR. Immune reconstitution syndrome and exacerbation of infections after pregnancy. Clinical Infectious Diseases, Volume 45, Issue 9, 1 November 2007, Pages 1192-1199. Available online https://doi.org/10.1086/522182.

19. Halperin SA, Langley JM, Ye L, et al. A Randomized Controlled Trial of the Safety and Immunogenicity of Tetanus, Diphtheria, and Acellular Pertussis Vaccine Immunization During Pregnancy and Subsequent Infant Immune Response. Clinical Infectious Diseases, Volume 67, Issue 7, 1 October 2018, Pages 1063-1071. Available online: https://doi.org/10.1093/cid/ciy244.

20. Kay AW, Blish CA. Immunogenicity and clinical efficacy of influenza vaccination in pregnancy. Front Immunol. 2015; 6: 289. Available online: 10.3389/fimmu.2015.00289.

21. Munoz FM, Jackson LA, Swamy GK, et al. Safety and immunogenicity of seasonal trivalent inactivated influenza vaccines in pregnant women. Vaccine. 2018 Dec 18;36(52): 8054-8061.

22. Sur DK, Wallis DH, O'Connell TX. Vaccination in pregnancy. Am Fam Physician. 2003 Jul 15;68(2):299-309. Available online: https://www.aafp.org/afp/2003/0715/p299.pdf.
23. World Health Organization. Global Advisory Committee on Vaccine Safety. Safety of immunization during pregnancy. Review of the evidence. 2014. Assessed online at https://www.who.int/vaccine_safety/publications/s afety_pregnancy_nov2014.pdf.

24. Soma-Pillay $P$, Nelson-Piercy C, Heli $T$, et al. Physiological changes in pregnancy. Cardiovascular $\mathrm{J}$ Afr. 2016 Mar-Apr; 27(2): 89-94. Available online: https://www.ncbi.nlm.nih.gov/pmc/articles/PMC49 28162/pdf/cvja-27-89.pdf.

25. Siston AM, Rasmussen $S A$, Honein $M A$, et al. Pandemic 2009 Influenza $A(H 1 N 1)$ Virus Illness Among Pregnant Women in the United States. JAMA. 2010;303(15):1517-1525. Available online: doi: 10.1001/jama.2010.479.

26. Jamieson DJ, Theiler RN, Rasmussen SA. Emerging infections and pregnancy. Emerg Infect Dis. 2006 Nov; 12(11): 1638-1643.

27. Wong SF, Chow KM, Leung TN. Pregnancy and perinatal outcomes of women with severe acute respiratory syndrome. Am J Obstet Gynecol. 2004 Jul; 191(1): 292-7.

28. Stockman LJ, Lowther SA, Coy K, et al. SARS during pregnancy, United States. Emerg Infect Dis. 2004 Sep; 10(9): 1689-1690. Available online: https://www.ncbi.nlm.nih.gov/pmc/articles/PMC33 20293/pdf/04-0244.pdf.

29. Zhang JP, Wang $\mathrm{YH}$, Chen $\mathrm{LN}$, et al. Clinical analysis of pregnancy in second and third trimesters complicated severe acute respiratory syndrome. Zhonghua Fu Chan Ke Za Zhi. 2003 Aug; 38(8):51620.

30. Jeong SY, Sung SI, Sung JH, et al. MERS-CoV Infection in a pregnant woman in Korea. J Korean Med Sci. 2017 Oct; 32(10): 1717-1720. Available online: https://www.ncbi.nlm.nih.gov/pmc/articles/PMC55 92190/pdf/jkms-32-1717.pdf.

31. Alserehi H, Wali G, Alshukairi A, Alraddadi B. Impact of Middle East Respiratory Syndrome coronavirus (MERS-CoV) on pregnancy and perinatal outcome. BMC Infect Dis. 2016 Mar 2;16:105. Available online doi: 10.1186/s12879-016-1437-y.

32. Assiri A, Abedi GR, Masri MA, et al. Middle East Respiratory syndrome coronavirus infection during pregnancy: a report of 5 cases from Saudi Arabia. Clin Infect Dis. 2016 Oct 1;63(7):951-3. Available online doi: 10.1093/cid/ciw412. 
International Journal of Integrative Pediatrics and Environmental Medicine, V5, 2020, 8-13

33. Racicot K, Mor G. Risks associated with viral infections during pregnancy. J Clin Invest. 2017 May 1; 127(5): 1591-1599. Available online: https://www.ncbi.nlm.nih.gov/pmc/articles/PMC54 09792/pdf/jci-127-87490.pdf.

34. Chen H, Guo J, Wang C, Luo F et al. Clinical characteristics and intrauterine vertical transmission potential of COVID-19 infection in nine pregnant women: a retrospective review of medical records. Lancet. 2020;395(10226):809. Available online: https://www.thelancet.com/action/showPdf?pii=S0 140-6736\%2820\%2930360-3.

35. Zhu $\mathrm{H}$, Wang L, Fang $\mathrm{C}$, Peng $\mathrm{S}$ et al. Clinical analysis of 10 neonates born to mothers with 2019-nCoV pneumonia. TransIPediatr. 2020;9(1):51. Available online: https://www.ncbi.nlm.nih.gov/pmc/articles/ PMC7036645/pdf/tp-09-01-51.pdf.
36. China CCDC. Novel Coronavirus Pneumonia Emergency Response Epidemiology Team. Vital surveillance: The epidemiological characteristics of an outbreak of 2019 novel coronavirus disease (COVID-19) - China, 2020. February 17, 2020. Available online: http://weekly.chinacdc.cn/en/ article/id/e53946e2-c6c4-41e9-9a9b-fea8db1a8f51.

37. The American College of Obstetricians and Gynecologists. Practice Advisory: Novel Coronavirus 2019 (COVID019), Published online on March 13, 2020. Available online at https://www.acog.org/Clinical-Guidance-andPublications/Practice-Advisories/Practice-AdvisoryNovel-Coronavirus2019 